\title{
Identification of a novel mutation in the factor VIII gene causing severe haemophilia A
}

\author{
S. K. Nissen ${ }^{1,2}$, A. L. Laursen ${ }^{1}$, L. H. Poulsen ${ }^{3}$ and T. H. Mogensen ${ }^{1,2^{*}}$ (D)
}

\begin{abstract}
Background: Deficiency in coagulation factor VIII encoded by F8 results in the X-linked recessive bleeding disorder haemophilia A (HEMA). Here we describe the identification of a novel variant in the factor VIII gene, F8, in an adult male patient with severe haemophilia A.

Case presentation: The patient was diagnosed in early childhood and subsequently co-infected with Hepatitis C and HIV acquired during early blood transfusion for haemophilia in the 1980ies. The identified F8 deletion, c.5411_5413delTCT, p.F1804del lies within a conserved part of the molecule, is predicted by bioinformatic software to be deleterious by the loss of Phenylalanine, and has not been previously described in any database.

Conclusion: This novel F8 deletion as a cause of haemophilia A did not result in generation of inhibitory antibodies to Factor VIII treatment and may have impact on (prenatal) diagnosis, genetic counselling, and treatment decisions in the affected family as well as in other families diagnosed with this F8 mutation. Finally, this novel mutation should be included in the panel of known genetic variants in F8 when searching for the genetic etiology in patients suspected of HEMA.
\end{abstract}

Keywords: Haemophilia, Factor 8 gene mutation, Whole exome sequencing

\section{Background}

Deficiency in coagulation factor VIII encoded by $F 8$ results in the X-linked recessive bleeding disorder haemophilia A (HEMA). HEMA occurs in 1:5.000-10.000 males with approximately one third of the cases being spontaneous mutations. The more than $180 \mathrm{~kb}$ long $F 8$ gene consists of 26 exons encoding a 2351 amino acids (AA) long precursor protein. The native protein consists of six domains: A1-A2-B-A3-C1-C2 and is cleaved into a heavy chain and a light chain structure by thrombin (Fig. 1a) [1, 2]. Several different mutations can lead to factor VIII deficiency. Whereas large intron inversions are responsible for almost half of the HEMA cases, deletions, duplications, and point mutations may also cause the disease [3-5]. HEMA is a diverse disease with a mild, moderate, and severe form with $\geq 5 \%, 2-5 \%$, and $\leq 1 \%$

\footnotetext{
* Correspondence: trinmoge@rm.dk

'Department of Infectious Diseases, Aarhus University Hospital, Aarhus, Denmark

${ }^{2}$ Department of Biomedicine, Aarhus University, Aarhus, Denmark

Full list of author information is available at the end of the article
}

remaining protein activity, respectively [1]. Knowledge on the severity caused by each specific mutation can be important during prenatal testing for management of pregnancy and delivery [6].

\section{Case presentation}

A 68-year-old male was diagnosed with severe HEMA in early childhood, with less than $0.001 \%$ factor VIII activity. The brother of the proband also suffered from severe HEMA, thus the mother must have been carrier of the causative mutation. The children of the proband were male, and consequently, in this part of the family the mutation has not been passed on. Due to the distant past of the diagnosis, no genetic tests had been performed to identify the causative mutation. Around 30\% of patients with severe HEMA develop inhibitors during their treatment with factor VIII, especially patients with large deletions and intron inversions. Thus, genetic factors can influence inhibitor development, and different treatment approaches are chosen according to risk of inhibitor development [7]. However, the proband never 
A

Native protein

1

1920

372

740

1689

2351

SP

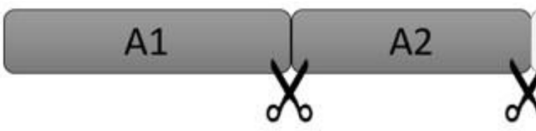

Mature protein

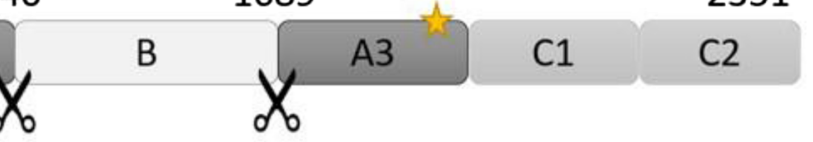

$\downarrow$ Cleavage by thrombin

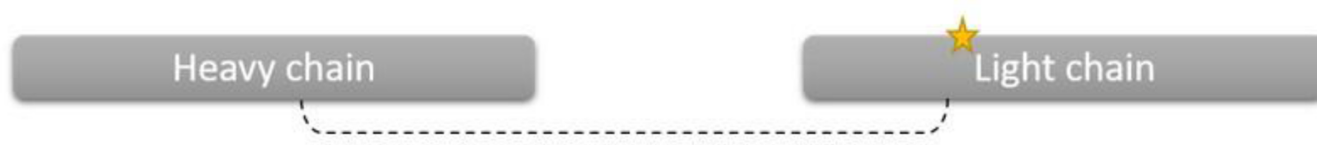

B

C

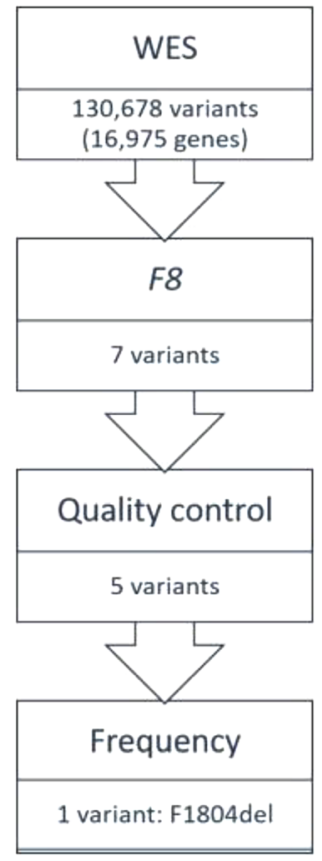
mRNA ... GCC UCU CGU CCC UAU UCC UUC cDNA ... CGG AGA GCA GGG ATA AGG AAG ATA AGA TCG GAA TAA AGA ...

Amino acid (AA)

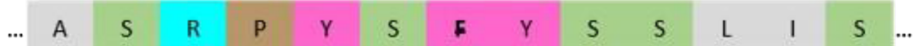

AA number

$\begin{array}{llllllllllllll}\text {... } 1798 & 1799 & 1800 & 1801 & 1802 & 1803 & 1804 & 1805 & 1806 & 1807 & 1808 & 1809 & 1810 & \ldots\end{array}$

After deletion

$\downarrow \downarrow \quad \downarrow \downarrow$

mRNA $\quad . . . G C C$ UCU CGU CCC UAU UCC - UAU UCU AGC CUU AUU UCU ...

CDNA

... CGG AGA GCA GGG ATA AGG

Amino acid (AA)

$\begin{array}{llllllll}\text {... } & \text { A } & S & R & P & Y & S\end{array}$

- ata aga tcg gaA taA aga ...

AA number

... 179817991800180118021803

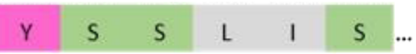

$\begin{array}{llllll}1805 & 1806 & 1807 & 1808 & 1809 & 1810 \ldots\end{array}$

D

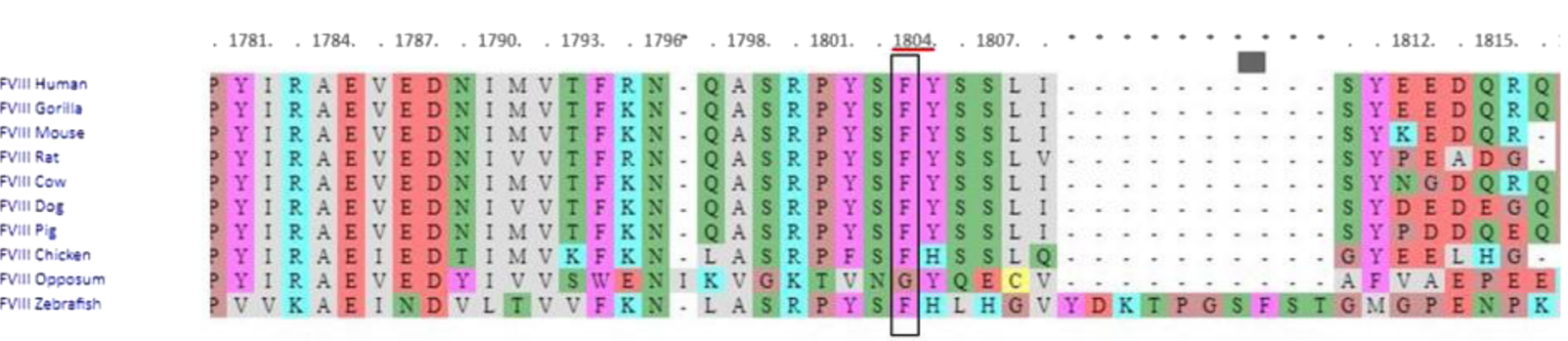

FVIII_HUMAN_P00451 | FVIII_GORILLA_G3QM23 | FVIII_MOUSE_Q06194 | FVIII_RAT_Q7TN96 | FVIII_COW_B9X245 | FVIII_DOG_O18806 | FVIII_PIG_P12263 | FVIII_CHICKEN_Q804X3 | FVIII_OPOSSUM_ENSMODT00000039634 | FVIII_ZEBRAFISH_ENSDART00000014159

Fig. 1 a Structure of novel and processed factor VIII protein. Signalling peptide (SP), novel mutation marked by star. $\mathbf{b}$ Identification of relevant variant by several filtering steps. c Section of the F8 gene, mRNA and factor VIII amino acid (AA) sequence with affected bases and AA high-lighted showing the resulting deletion in the Factor VIII molecule. $\mathbf{d}$ AA position examined for conservation in human, gorilla, mouse, rat, cow, dog, pig, chicken, oppossum, and zebrafish F8 using the publicly available multiple-sequence alignment (http://www.factorviii-db.org/sequence.html.php) 
developed factor VIII inhibitors, possibly suggesting a smaller and less frequent mutation in $F 8$ than the large intron inversion. Following blood transfusion, the proband was tested positive for HIV-1 and hepatitis $\mathrm{C}$ virus in the late 1980s and early 1990s, respectively. The patient was cured for his Hepatitis $\mathrm{C}$ infection, but never received any treatment for his HIV-1 infection, since he remained with normal CD4 T cell count over time and was considered an HIV long-term non-progressor (LTNP).

To identify the HEMA causative mutation (as well as possible mutations explanatory for his HIV LTNP phenotype), a blood sample was drawn in EDTA tubes (FLUKA), and peripheral blood mononuclear cells (PBMCs) were isolated over ficoll gradient (GE-healthcare). Integrating HIV DNA in CD4 T cells might result in false positive (somatic mosaic) mutations, or disturb the quality of sequencing. Therefore, CD4 T cells were depleted by magnetic purification (miltenyi biotec). DNA from non-CD4 $\mathrm{T}$ cells was purified using allprep DNA/RNA mini kit (Qiagen). Whole exome sequencing (WES) was performed employing Kapa HTP Library preparation and Nimblegen SeqCap EZ MedExome Plus kit and analysed using Nextseq v2 chemistry $(2 \times 150 \mathrm{bp})$. SNPs were called relative to hg19. Variant call files (VCF) were uploaded to Ingenuity Variant Analysis (IVA, Qiagen) and variants were compared to population frequencies of variants in the Allele Frequency Community (AFC) database and to frequencies in the 1000 Geneomes project. One hundred thirty thousand six hundred eighty-seven variants were identified in 16,957 genes in the patient, of which seven were located in the $F 8$ gene. Two variants did not pass quality control, thus five variants could be possibly causative (see Table 1). Four of the remaining variants had an allele frequency much higher than the disease frequency and were therefore judged as being irrelevant. Therefore, one variant (c.5411_5412delTCT, p.F1804del) remained a potential cause of disease (Fig. 1b). The mutation was verified in the raw BAM file (Additional file 1: Figure S1). Ingenuity did not provide any dbSNP ID or frequency for this variant, which is thus denoted as novel. Moreover, the variant was not reported in Coagulation Factor Variant Databases
EAHAD.CFDB (https://databases.lovd.nl/shared/variants/ $F 8$ ), which provides all 5418 known transcript variants in the F8 gene, confirming that the c.5411_5413delTCT, p.F1804del must indeed be novel.

\section{Discussion and conclusion}

The three deleted bases in $F 8$ are distributed with two located in the end of F1804-codon and one in the beginning of Y1805-codon. The remaining bases from the two codons will fuse as new Tyr codon (see Fig. 1c). Thus, the three base deletion results in an in-frame p.F1804 deletion located in exon 16 in the A3 domain/light chain structure (Fig. 1c). This functional domain is highly conserved throughout evolution (Fig. 1d), stressing the importance of these specific AA in this area for a functional protein. Consequently, Ingenuity software predicts this deletion to be "likely pathogenic", since it is 1) located in a critical and well-established domain without benign variation; 2) absent from controls; 3 ) and the protein length change in a non-repeat region. The F1804del variant was predicted to result in loss of function of the protein, whereas the more common variants were all predicted to have normal function or gain of function with low CADD score, thus interpreted as benign. Furthermore, a natural variant affecting the neighbouring AA (S1803Y, dbSNP:rs137852444) results in severe HEMA [8], and two natural variants affecting the same AA by substitution instead of deletion also result in severe HEMA, further supporting a disease causing role of the identified mutation. Finally, intron inversions responsible for the majority of HEMA cases were not identified in this patient. Taken together, these data indicate that c.5411_5413delTCT/p.F1804del is the causative mutation in the index patient.

Here we describe the identification of a novel deletion, p.F1804del in F8 causing severe HEMA. Importantly, this novel deletion mutant did not result in generation of inhibitory antibodies to Factor VIIII treatment. The results from the present study demonstrate that WES can be used as a tool for identification of rare non-intron inversion mutations in $F 8$, where PCR and denaturing gradient

Table 1 Identified genetic variants passing quality control

\begin{tabular}{|c|c|c|c|c|c|c|c|c|c|c|}
\hline Transcript Variant & $\begin{array}{l}\text { Protein } \\
\text { Variant }\end{array}$ & $\begin{array}{l}\text { Gene } \\
\text { Region }\end{array}$ & $\begin{array}{l}\text { Variant } \\
\text { Type }\end{array}$ & Activity & Classification & Impact & $\begin{array}{l}\text { CADD } \\
\text { Score }\end{array}$ & $\begin{array}{l}\text { dbSNP } \\
\text { ID }\end{array}$ & $\begin{array}{l}\text { AFC } \\
\text { Freq. }\end{array}$ & $\begin{array}{l}1000 \text { Genomes } \\
\text { Freq. }\end{array}$ \\
\hline c. $6115+103 \mathrm{~T}>\mathrm{C}$ & & Intronic & SNV & normal & Benign & & $<10$ & $4,074,307$ & 22.442 & 44.079 \\
\hline c. $5998+91 \mathrm{~T}>\mathrm{A}$ & & Intronic & SNV & normal & Benign & & $<10$ & $4,898,352$ & 22.653 & 44.132 \\
\hline c.5411_5413delTCT & p.F1804del & Exonic & Deletion & loss & $\begin{array}{l}\text { Likely } \\
\text { Pathogenic }\end{array}$ & in-frame & * & & & \\
\hline c. $3780 C>G$ & p.D1260E & Exonic & SNV & gain & Benign & missense & $<10$ & $1,800,291$ & 18.924 & 25.642 \\
\hline c. $1010-27 G>A$ & & Intronic & SNV & normal & Benign & & $<10$ & $7,058,826$ & 11.328 & 7.735 \\
\hline
\end{tabular}

Transcript ID NM_000132.3, chromosome X, cytoband q28, gene F8. * CADD score can not be estimated for deletions

Freq frequency, $C A D D$ combined annotation dependent depletion 
gel electrophoresis (DGGE) have been found inadequate to detect the HEMA causative mutation. Sanger sequencing may be used to examine for this variant in potential female carriers in the family of the index patient or for future prenatal diagnosis in the family. The identification of this specific F8 deletion in an individual may have impact on genetic counselling, treatment decisions, and prediction of prognosis. Based on the present report, the $F 8$ p.F1804del is expected to predict a severe clinical phenotype of HEMA but possibly without generation of inhibitory antibodies to Factor VIII treatment. Finally, this novel mutation should be included in the panel of known genetic variants in $F 8$ when searching for the specific genetic etiology in patients suspected of HEMA.

\section{Additional file}

Additional file 1: Figure S1. BAM file aligned to the F8 gene in the UCSC genome browser. The three base deletion is visualized with absent alignment of library CDNA in both reading directions (red and blue). (DOCX $1688 \mathrm{~kb})$

\section{Abbreviations}

AA: Amino acid; HEMA: Haemophilia A; LTNP: Long-term non-progressor; SNP: Single nucleotide polymorphism; WES: Whole exome sequencing

\section{Acknowledgements}

The authors wish to thank the patient for participating in the study.

\section{Funding}

THM received a grant from the Danish Council for Independent Research (\#6110-00140B). The funding body did not have any influence on in the design of the study and collection, analysis, and interpretation of data and in writing the manuscript.

\section{Availability of data and materials}

All relevant data are included in the manuscript. For further details the corresponding author may be contacted.

\section{Authors' contributions}

SKN and THM designed the research study; ALL and LHP collected clinical information; SKN carried out the research and wrote the first draft of the manuscript; all authors read and approved the final version of the manuscript.

\section{Ethics approval and consent to participate}

This study was approved by the Danish Reginal Ethics Committee (1-10-72-369-14). Moreover, the patient described provided his oral and written consent to participate.

\section{Consent for publication}

The patient provided written consent for publication of potentially-identifying information.

\section{Competing interests}

The authors declare that they have no competing interests.

\section{Publisher's Note}

Springer Nature remains neutral with regard to jurisdictional claims in published maps and institutional affiliations.

\section{Author details}

'Department of Infectious Diseases, Aarhus University Hospital, Aarhus, Denmark. ${ }^{2}$ Department of Biomedicine, Aarhus University, Aarhus, Denmark.
${ }^{3}$ Centre for Haemophilia and Thrombosis, Department of Clinical

Biochemistry, Aarhus University Hospital, Aarhus, Denmark.

Received: 8 November 2017 Accepted: 25 July 2018

Published online: 31 July 2018

References

1. Bicocchi MP, Pasino M, Lanza T, Bottini F, Boeri E, Mori PG, Molinari AC, Rosano C, Acquila M. Analysis of 18 novel mutations in the factor VIII gene. $\mathrm{Br} J$ Haematol. 2003;122:810-7. published online EpubSep

2. Graw J, Brackmann HH, Oldenburg J, Schneppenheim R, Spannagl M, Schwaab R. Haemophilia A: from mutation analysis to new therapies. Nat Rev Genet. 2005); published online EpubJun;6:488-501. https://doi.org/10. 1038/nrg1617.

3. Lakich D, Kazazian HH Jr, Antonarakis SE, Gitschier J. Inversions disrupting the factor VIII gene are a common cause of severe haemophilia A. Nat Genet. 1993); published online EpubNov;5:236-41. https://doi.org/10.1038/ ng1193-236.

4. Bagnall RD, Waseem N, Green PM, Giannelli F. Recurrent inversion breaking intron 1 of the factor VIII gene is a frequent cause of severe hemophilia A. Blood. 2002;99:168-74. published online EpubJan 01

5. Peyvandi F, Kunicki T, Lillicrap D. Genetic sequence analysis of inherited bleeding diseases. Blood. 2013); published online EpubNov 14;122:3423-31. https://doi.org/10.1182/blood-2013-05-505511.

6. Street AM, Ljung R, Lavery SA. Management of carriers and babies with haemophilia. Haemophilia. 2008); published online EpubJul;14(Suppl 3):181-7. https://doi.org/10.1111/j.1365-2516.2008.01721.x.

7. Bogdanova N, Markoff A, Pollmann H, Nowak-Gottl U, Eisert R, Wermes C, Todorova A, Eigel A, Dworniczak B, Horst J. Spectrum of molecular defects and mutation detection rate in patients with severe hemophilia A. Human Mutat. 2005); published online EpubSep;26:249-54. https://doi.org/10.1002/ humu.20208.

8. Higuchi M, Kazazian HH Jr, Kasch L, Warren TC, McGinniss MJ, Phillips JA 3rd, Kasper C, Janco R, Antonarakis SE. Molecular characterization of severe hemophilia A suggests that about half the mutations are not within the coding regions and splice junctions of the factor VIII gene. Proc Natl Acad Sci U S A. 1991;88:7405-9. published online EpubAug 15

Ready to submit your research? Choose BMC and benefit from:

- fast, convenient online submission

- thorough peer review by experienced researchers in your field

- rapid publication on acceptance

- support for research data, including large and complex data types

- gold Open Access which fosters wider collaboration and increased citations

- maximum visibility for your research: over $100 \mathrm{M}$ website views per year

At $\mathrm{BMC}$, research is always in progress.

Learn more biomedcentral.com/submission 